Check for updates

London

Cite this as: BMJ 2021;372:n152 http://dx.doi.org/10.1136/bmj.n152 Published: 18 January 2021

\title{
Disparity in maternal deaths because of ethnicity is "unacceptable"
}

\section{Matthew Limb}

Urgent action is needed to tackle systemic biases contributing to unequal mortality outcomes in ethnic minority women and women facing multiple problems and deprivation, say experts.

The authors of a new analysis of maternal deaths in the UK, ${ }^{1}$ issued by Oxford University's Nuffield Department of Population Health, say that the coronavirus pandemic is likely to have worsened the disparities they have highlighted.

Black women are four times more likely than white women to die in pregnancy or childbirth, says the seventh annual report from MBRRACE-UK (Mothers and Babies: Reducing Risk through Audits and Confidential Enquiries). ${ }^{1}$ Women from Asian ethnic backgrounds face a twofold risk, and women living in the most deprived areas of the UK are almost three times more likely to die than those in the most affluent areas.

The report includes surveillance data on women in the UK who died during pregnancy or up to one year afterwards in 2016-18 and details the lessons for maternity that can be learnt care from confidential inquiries.

The number of women known to have been experiencing multiple disadvantages when they died has increased by a third since the previous report in 2019 , from $6 \%$ to $8 \%$. Women in these situations often face mental ill health or domestic abuse and may misuse substances.

\section{Wider action}

Maggie Rae, president of the Faculty of Public Health, said, "Women who live in more deprived areas continue to be at greater risk of dying during or after pregnancy, and many of the complex factors underlying this increased risk need action much more widely than in maternity services, beyond the health sector, and often long before pregnancy.

"We will need to address this challenge of wider system actions in order to reduce deaths of women during or after pregnancy as well as their babies."

The report said that pregnancy remained "very safe" in the UK. In 2016-18, 547 women died during or up to a year after pregnancy from causes associated with their pregnancy, among 2.2 million women who gave birth in the UK. In that period 34 Black women died among every 100 ooo giving birth, compared with 15 Asian women in 100 ooo, and eight white women in 100000.

The report said that these figures were

"fundamentally unchanged" from those documented in the 2019 report and that, despite encouraging responses to this disparity from groups including the NHS and government agencies, sustained focus was needed.
Marian Knight, lead author for MBRRACE-UK and professor of maternal and child population health at the University of Oxford, said that disparity in maternal mortality simply because of a woman's ethnicity was recognised as "unacceptable.” She added, "It is equally unacceptable for women with pre-existing medical conditions such as epilepsy to receive a lower standard of care simply because they are pregnant."

The analysis reported a "concerning rise"-almost doubled from the previous three years-in maternal mortality due to sudden unexpected death in epilepsy (SUDEP). In many instances these deaths were linked to inadequate medicine management for these women either before or during their pregnancy.

Knight said, "Systemic biases prevent women with complex and multiple problems receiving the care they need. This needs to be addressed urgently, particularly since the impacts of social and ethnic inequalities, multiple disadvantages, and epilepsy are likely to have been amplified during the covid-19 pandemic."

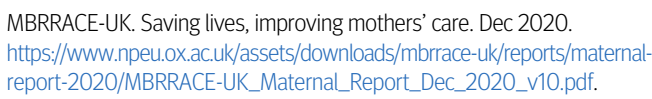

